\title{
EFFICIENCY OF RETENTION OF TWO ATTACHMENT DESIGNS USED FOR ALL ON FOUR MANDIBULAR INCLINED IMPLANTS ASSISTED OVERDENTURE (IN VITRO STUDY)
}

\author{
Nermine M. El-Sehly ${ }^{1 * B D s}$, Ahmed M. Abdel-Hamid ${ }^{2} P h D$, Nermeen A. Rady $P h D$, \\ Ahmed H. Elbanna ${ }^{4} P h D$.
}

\begin{abstract} concept. all-on-four theory after and before cyclic loading. cycling loading then compared with control group. loading for the two groups $(\mathrm{p}<0.001)$. Positioner attachment group after and before cyclic loading.

KEYWORDS: Implant overdenture, tilted implants, OT Equator, Smart box, Angled positioner.

RUNNING TITLE: Retention of two attachments in all-on-four.

1 BDS, Faculty of Dentistry, Alexandria University, Alexandria, Egypt.

2 Professor of Prosthodontics, Alexandria University, Alexandria, Egypt.

3 Lecturer of Prosthodontics, Faculty of Dentistry, Alexandria University, Alexandria, Egypt.

4Lecturer of Dental Biomaterials, Faculty of Dentistry, Ain Shams University, Cairo, Egypt.
\end{abstract}

INTRODUCTION: Reduction of retention should be considered when selecting an attachment for inclined implants following the all-on-four

OBJECTIVES: Evaluation the force of retentivity of mandibular implant-assisted overdentures with 2 dissimilar abutment designs following the

MATERIAL AND METHODS: Two identical completely edentulous mandible models were made with epoxy resin. Anterior 2 implants were set parallel to one another in the symphyseal area and two tilted implants were put distally inclined with 25 degree angulation at canine-1st premolar region of each model by using a 3D Printed surgical guide. For group I (study group/1st model) OT-Equator abutment was attached to the anterior parallel implants and OT-Equator with smart box abutment was linked to the tilted implants. Group II (control group/2nd model) using OT-Equator abutment linked to the anterior parallel implants and angled positioner abutment linked to tilted implants. A universal testing machine was used to evaluatethe force of retentivity was of all overdentures with different attachments following the all-on-four concept before and after

RESULTS: When force of retentivity of altogether overdentures with different attachments following the all-on-four concept after and before cyclic loading were compared, there was significant difference of force of retentivity between different resilient caps which decreased after cyclic

CONCLUSIONS: The OT-Equator with smart box attachment group showed greater value of force of retentivity compared with the Angled

*Corresponding author:

E-mail: Mohamed_nermine@yahoo.com

\section{INTRODUCTION}

Implant-retained and-supported Overdentures (IRO, ISO) have been proposed during last decades for restoring completely edentulous patients, as an alternative and more effective treatment modality to the traditional detachable complete denture (CD). High long-term success rates and improved patients' life quality were reported for IRO and ISO $(1,2)$.

In few cases of the edentulous patients with severe resorption in the posterior region of the mandible, prosthesis supported by implant treatment needs complex techniques like transposition of the nerve in addition to graft in the posterior region of the mandible. One of the solutions in these cases is the All- on-4 concept. This method requires the distal implants to be at an angle in edentulous ridges allowing the placement of implants of greater length, , enhanced anchorage in the bone, enhanced inter implant distance and enhanced prosthetic sustenance with shorter cantilever arm (3).

Tilted implants may necessities using angled abutments to obtain a parallel path of insertion and/or removal of the final prosthesis. These abutments improve the direction of the emergence profile moreover allowing for a degree of parallelism with anterior and posterior implants. The clinical inculpation of angled abutments showed multiple defects.

Additional materials, time and expense are required for the impression, transitional prosthesis and definitive restoration. 
With an increase in technique, complexity also emanates the increase in potential error (4).

Multiple systems of attachment have been used as retentive components for overdenture on root and are being used completely for the stabilization of overdenture to the installed as implants, including bars, magnets ,balls, and telescopic attachments (5).

As stated by a current Cochrane Systematic Review (6), there isn't any necessary indication to regulate the true efficiency of diverse systems of attachment for mandibular overdentures, on patient's needs and satisfaction, prosthodontics success, maintenance, and costs. Though, OT Equator design syndicates the ball attachments simplicity and suggest several exclusive profits that the other systems can't.

A significantly lower height, and smaller diameter, solving the problem of non-paralleled implants, hygienic construction and reasonable price are the primary advantages (7).

The new Smart Box attachment used in extremely diverged cases between the implants with the OT Equator, the smallest implant attachment on the market. An inner mechanism of tilting is a feature in the new Smart Box allowing a passive insertion using different implants fit for 50 degrees (8).

The hypothesis of this study was to measure and compare the force of retentivity of angled positioner and OT-Equator with smart box in all on four mandibular implant assisted overdenture (IAO) before and after cyclic loading using the universal testing machine.

The insignificant hypothesis was that there is no significant difference on the force of retentivity of the two different attachment systems.

\section{MATERIAL AND METHODS}

Two symmetrically edentulous mandibular model made of epoxy resin were used (9) (Ramses Medical Factory) with a width of $7.50 \mathrm{~mm}$ in the interbicuspid region. A mucosamimicking material made of flexible polyurethane (Mollosil, Detax Co. Ettlingen/Germany) of $2.50 \mathrm{~mm}$ in thickness was used to cover the epoxy resin.

A 3D printed surgical guide (Form labs, Somerville, MA, USA) was used to ensure the precise location of bilateral posterior implant drilling with 25.0 degree angulation after scanning of the epoxy model. Two implants (Dentium superline, Dentium Co. Ltd., Korea) of $10.0 \mathrm{~mm}$ in length and $4.0 \mathrm{~mm}$ in diameter were installed anteriorly parallel in the symphyseal area and two tilted implants of $14.0 \mathrm{~mm}$ in length and 4.0 $\mathrm{mm}$ in width were placed at canine-1st premolar region distally inclined with 25.0 degree angulation in the two identical models by using a torque wrench following the all on four concept. The primary stability was $35 \mathrm{Ncm}$.

Two abutment systems were used: the OT-Equator (Ref.335SBC, Rhein83, Italy) with smart box (Ref.030, Rhein83, Italy) abutment and the Angled Positioned (Neodent GM Novalok) (Fig. 1). Each OT-Equator abutment was screwed to each implant by using a torque wrench (Dental Evolution Inc) to a torque of $20.0 \mathrm{Ncm}$.

The models were used for construction of overdentures which divided into two groups using one model for each group. For group I (study group/1st model) with OT-Equator abutment was linked to the anterior parallel implants and OT-Equator with smart box was linked to the tilted implants. Group II (control group/2nd model) using OT-Equator abutment linked to the anterior parallel implants and angled positioner abutment linked to tilted implants (Fig. 2).
A

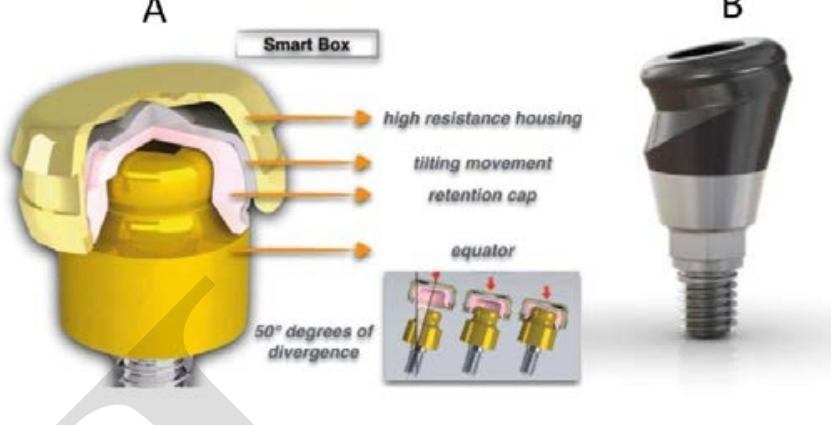

Figure (1): Diagram showing OT-Equator with smart box attachment(A) and Angled Positioner attachment (B).

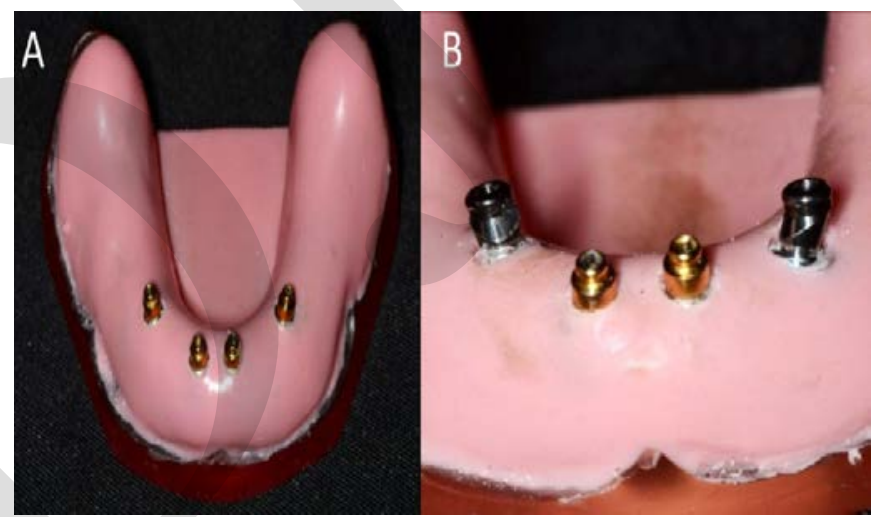

Figure (2): Model (A) with OT-Equator abutment, .Model(B) with Angled Positioner abutment.

The epoxy model was duplicated into sixteen stone casts by using vacuum mixed type III dental stone on which 16 identical mandibular overdenture bases with wax occlusal rims and an acrylic resin vertical plate was attached to the occlusal rims at premolar/molar area to be attached to the universal testing machine, heat-polymerizing resin (Denture Base Material; Acrostone Co Ltd) was used to flask and pack eight for each group , while the conventional standerdized technique was used to finish and polish them (Fig. 3).

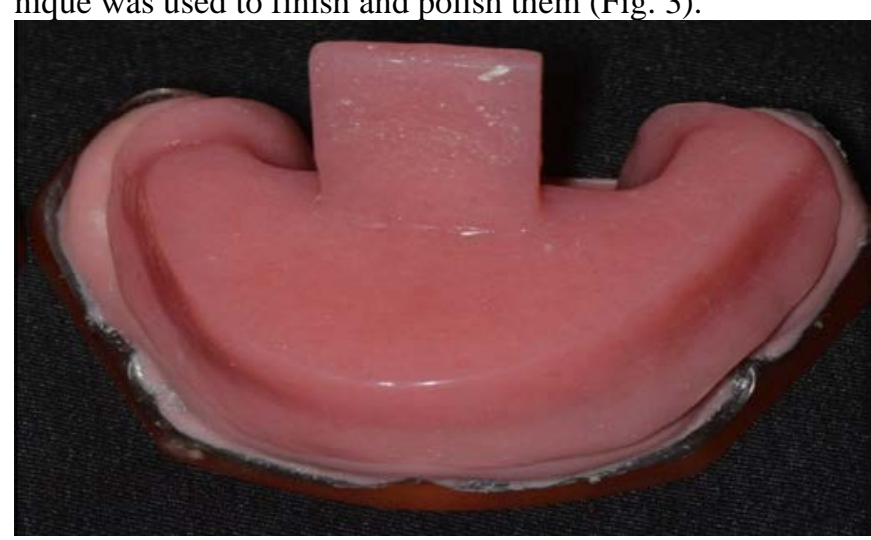

Figure (3): Overdenture with $90^{\circ}$ acrylic extension on epoxy resin model. 
For direct pick-up of attachments into overdenture, block out spaces were placed over the head of each OT-Equator abutment and then metal sockets with (black processing caps) were snapped on. The areas over the housings were relieved with an acrylic bur until the denture can be fully seated passively on the model, a mix of autopolymerized acrylic resin "pick-up material" was made, and the spaces were filled using a plastic filling instrument, under pressure for 4 minutes to allow for polymerization to occur. The denture was removed and the spaces were discarded. The OT-Equator core tool was used for the procedure of removing the black processing caps from the socket and replacing it with the different nylon caps (Fig. 4, 5).

To measure the force of retentivity of overdenture with different types of attachments, a universal testing machine (Multi Test5-XT; Mecmesin Corp) was used. The model was attached to the lower member of the universal testing machine via the custom-made 90-degree device (Fig. 6). The acrylic resin vertical plate and the upper member of the universal testing machine are attached together to offer a tensile dislodging force to the overdentures (10). Therefore, a tensile force was applied on a perpendicular direction to the occlusal plane as probable to simulate a denture's axially focused dislodging forces.

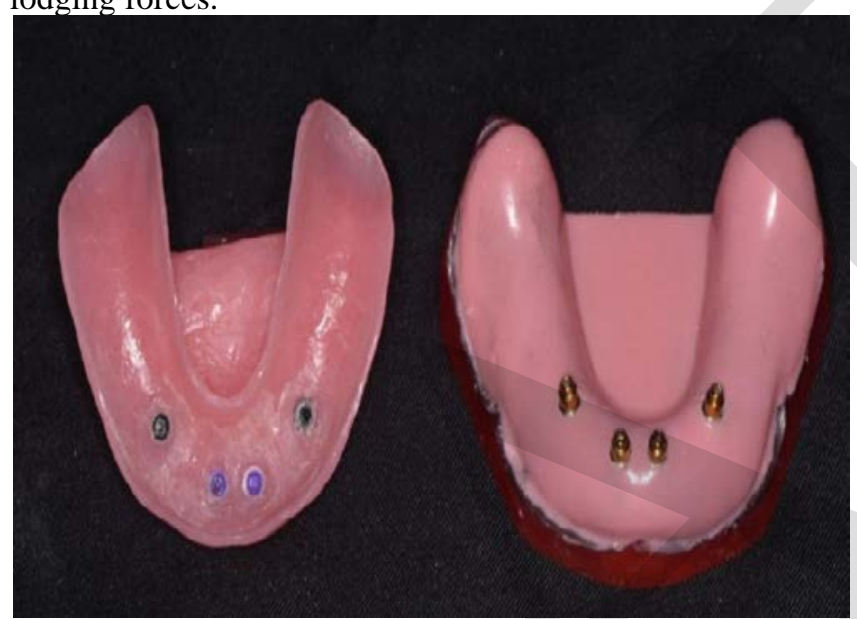

Figure (4): Showing fitting surface of the overdenture with OT-Equator caps and Smart Box.

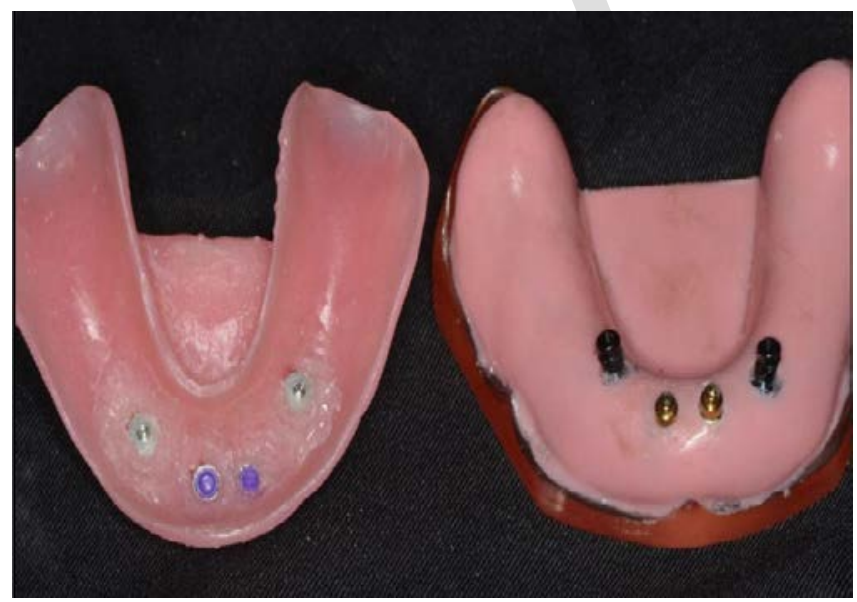

Figure (5): Showing fitting surface of the overdenture with Angled Positioner caps.

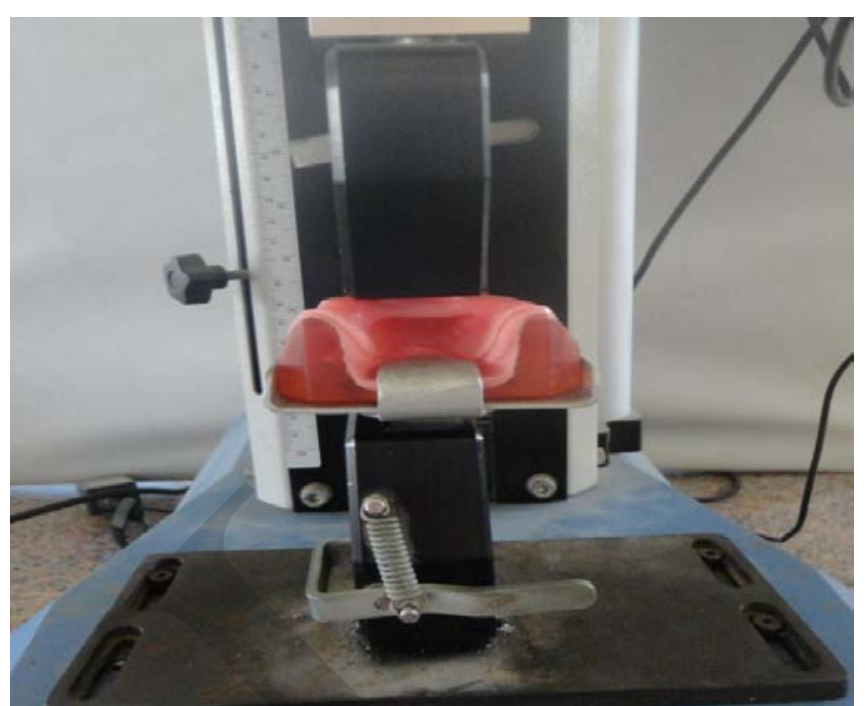

Figure (6): The universal testing machine dislodging the overdenture.

Withdraw the overdenture is done through setting the crosshead speed of the universal testing machine at $50.0 \mathrm{~mm} / \mathrm{min}$ to mimic the dislodging speed of prosthesis from the residual alveolar ridge during mastication (11) and up to an extension of $5.0 \mathrm{~mm}$.

In order to determine the initial force of retentivity of each attachment system, Peak load to dislodgement was noted .

A custom-made cyclic loading machine that represented a dental mastication simulator was used to perform a cyclic tension-compression test in a vertical direction. Custom-made cyclic loading machine acted as a dental mastication simulator to simulate the removal and insertion of the 16 overdentures. Each overdenture was exposed to 1000 cycles in one year based on an average of 3 removal-insertion cycles per day $(12,13)$.

The universal testing machine was used to report the dislodgment of the overdenture through measuring the final force of retentivity, in addition to the crosshead speed of $50 \mathrm{~mm} / \mathrm{min}$ and up to an extension of $5.0 \mathrm{~mm}$. Recordation of the peak load to dislodgment was done to decide the final force of retentivity of each attachment system. The needed forces of dislodgment of the overdentures was measured prior to and following to the tension-compression cycles. The resulted variance stipulated the depletion in the retention from usage.

\section{Statistical analysis}

Data were fed to the computer and analyzed using IBM SPSS software package version 20.0. (Armonk, NY: IBM Crop). The Kolmogorov-smirnov test was used to verify the normality of distribution. Quantitative data were described using range (minimum and maximum), mean, standard deviation, median and interquartile range (IQR). Significance of the obtained results was judged at the $5 \%$ level. The used tests were, student t-test for normally distributed quantitative variables, to compare between two studied groups and paired t-test for normally distributed quantitative variables, to compare between two periods. 


\section{RESULTS}

Data were collected, tabulated and statistically presented as follows:

A statistically significant difference was found between the force of retentivitys of the standard resilient nylon caps of the OT-Equator with smart box group (study group) and Angled Positioner group (control group), which decreased after cyclic loading with a median (33.65-31.35) and (26.35-22.45) respectively $(\mathrm{p}<.001)($ table 1$)$.

Table (1): Comparison between the OT-Equator with smart box attachment and angled positioner attachment according to force of retentivity of standard resilient caps

\begin{tabular}{|c|c|c|c|c|}
\hline $\begin{array}{c}\text { Standard reten- } \\
\text { tion }\end{array}$ & $\begin{array}{c}\text { Group I } \\
\text { (study group) } \\
(\mathbf{n}=\mathbf{8})\end{array}$ & $\begin{array}{c}\text { Group II } \\
\text { (study group) } \\
(\mathbf{n}=\mathbf{8})\end{array}$ & $\mathbf{t}_{1}$ & $\mathbf{p}_{1}$ \\
\hline $\begin{array}{l}\text { Before cycling } \\
\text { loading }\end{array}$ & & & & \\
\hline Min. - Max. & $32.90-34.20$ & $25.90-26.80$ & & \\
\hline $\begin{array}{l}\text { Mean } \pm \text { SD. } \\
\text { Median(IQR) }\end{array}$ & $\begin{array}{c}33.58 \pm 0.39 \\
33.65 \\
(33.35-33.75)\end{array}$ & $\begin{array}{c}26.38 \pm 0.32 \\
26.35 \\
(26.15-26.65)\end{array}$ & $40.272^{*}$ & $01^{*}$ \\
\hline $\begin{array}{l}\text { After cycling } \\
\text { loading }\end{array}$ & & & & \\
\hline Min. - Max. & $30.90-31.80$ & $22.10-22.90$ & & \\
\hline Mean \pm SD & $31.36 \pm 0.30$ & $22.50 \pm 0.28$ & $61.086^{*}$ & $<0.001^{*}$ \\
\hline Median(IQR) & $\begin{array}{c}31.35 \\
(31.15-31.60)\end{array}$ & $\begin{array}{c}22.45 \\
(22.30-22.75)\end{array}$ & & \\
\hline $\mathbf{t}_{2}\left(\mathbf{p}_{2}\right)$ & $12.741^{*}\left(<0.001^{*}\right)$ & $22.678^{*}\left(<0.001^{*}\right)$ & & \\
\hline Decrease & & & & \\
\hline Min. - Max. & $1.30-2.70$ & $3.10-4.50$ & & \\
\hline Mean \pm SD & $2.21 \pm 0.49$ & $3.88 \pm 0.48$ & $6.824^{*}$ & $<0.001^{*}$ \\
\hline Median(IQR) & $2.35(1.90-2.60)$ & $3.85(3.55-4.30)$ & & \\
\hline$\%$ of Decrease & & & & \\
\hline Min. - Max. & $3.95-8.04$ & $11.97-16.85$ & & \\
\hline $\begin{array}{l}\text { Mean } \pm \text { SD. } \\
\text { Median(IQR) }\end{array}$ & $\begin{array}{c}6.58 \pm 1.41 \\
6.97(5.70-7.65)\end{array}$ & $\begin{array}{c}14.68 \pm 1.69 \\
4.53(13.57-16.20)\end{array}$ & $10.380^{*}$ & $<0.001^{*}$ \\
\hline
\end{tabular}

\section{$\mathbf{t}_{1}$ : Student t-test}

$t_{2}$ : Paired t-test

$\mathrm{p}_{1}$ : $\mathrm{p}$ value for comparing between the studied groups

$\mathrm{p}_{2}$ : $\mathrm{p}$ value for comparing between before and after cycling loading in each group

*: Statistically significant at $\mathrm{p} \leq 0.05$

Group I: OT-Equator with smart box attachment

\section{Group II: Angled positioner attachment}

A statistically significant increase of force of retentivity was found between the OT-Equator with smart box group (study group) when compared with the Angled Positioner group (control group) when the force of retentivitys of all different resilient nylon caps where compared with each other before and after cyclic loading $(\mathrm{p}<.001)$ (Tables 1,2 \&3).

Table (2): Comparison between the OT-Equator with smart box attachment and angled positioner attachment according to force of retentivity of soft resilient caps

\begin{tabular}{|c|c|c|c|c|}
\hline Soft retention & $\begin{array}{c}\text { Group I } \\
\text { (study group) } \\
(\mathbf{n}=\mathbf{8})\end{array}$ & $\begin{array}{c}\text { Group II } \\
\text { (control group) } \\
(\mathbf{n}=\mathbf{8})\end{array}$ & $\mathbf{t}_{1}$ & $\mathbf{p}_{1}$ \\
\hline $\begin{array}{l}\text { Before cycling } \\
\text { loading } \\
\text { Min. - Max. } \\
\text { Mean } \pm \text { SD. } \\
\text { Median(IQR) }\end{array}$ & $\begin{array}{c}31.20-32.10 \\
31.55 \pm 0.29 \\
31.50 \\
(31.35-31.70)\end{array}$ & $\begin{array}{c}24.20-25.10 \\
24.58 \pm 0.30 \\
24.55 \\
(24.35-24.75)\end{array}$ & $46.968^{*}$ & $<0.001^{*}$ \\
\hline $\begin{array}{l}\text { After cycling } \\
\text { loading } \\
\text { Min. - Max. } \\
\text { Mean } \pm \text { SD. } \\
\text { Median(IQR) }\end{array}$ & $\begin{array}{c}28.10-28.90 \\
28.43 \pm 0.32 \\
28.30 \\
(28.15-28.75)\end{array}$ & $\begin{array}{c}19.10-19.80 \\
19.36 \pm 0.22 \\
19.35 \\
(19.20-19.45)\end{array}$ & $65.447^{*}$ & $<0.001^{*}$ \\
\hline $\mathbf{t}_{2}\left(\mathbf{p}_{2}\right)$ & $\begin{array}{c}17.263^{*} \\
\left(<0.001^{*}\right)\end{array}$ & $\begin{array}{c}34.906^{*} \\
\left(<0.001^{*}\right)\end{array}$ & & \\
\hline $\begin{array}{l}\text { Decrease } \\
\text { Min. - Max. }\end{array}$ & $2.30-3.80$ & $4.40-5.90$ & & \\
\hline $\begin{array}{l}\text { Mean } \pm \text { SD. } \\
\text { Median(IQR) }\end{array}$ & $\begin{array}{c}3.13 \pm 0.51 \\
3.15 \\
(2.75-3.55)\end{array}$ & $\begin{array}{c}5.21 \pm 0.42 \\
5.30 \\
(5.05-5.35)\end{array}$ & $8.896^{*}$ & $<0.001^{*}$ \\
\hline $\begin{array}{l}\% \text { of Decrease } \\
\text { Min. - Max. }\end{array}$ & $7.37-11.84$ & $18.18-23.51$ & & \\
\hline $\begin{array}{l}\text { Mean } \pm \text { SD. } \\
\text { Median(IQR) }\end{array}$ & $\begin{array}{c}9.90 \pm 1.55 \\
10.05 \\
(8.73-11.20)\end{array}$ & $\begin{array}{c}21.20 \pm 1.50 \\
21.50 \\
(20.74-21.70)\end{array}$ & $14.820 *$ & $<0.001^{*}$ \\
\hline
\end{tabular}

\section{$t_{1}$ : Student t-test}

$t_{2}$ : Paired t-test

$\mathrm{p}_{1}$ : $\mathrm{p}$ value for comparing between the studied groups $\mathrm{p}_{2}: \mathrm{p}$ value for comparing between before and after cycling loading in each group

*: Statistically significant at $\mathrm{p} \leq 0.05$

Group I: OT-Equator with smart box attachment Group II: Angled positioner attachment 
Table (3): Comparison between the OT-Equator with smart box attachment and angled positioner attachment according to force of retentivity of extra soft resilient caps

\begin{tabular}{|c|c|c|c|c|}
\hline $\begin{array}{c}\text { Extra soft } \\
\text { retention }\end{array}$ & $\begin{array}{c}\text { Group I } \\
\text { (study group) } \\
(\mathbf{n}=8)\end{array}$ & $\begin{array}{c}\text { Group II } \\
\text { (control group) } \\
(\mathbf{n}=\mathbf{8})\end{array}$ & $t_{1}$ & $\mathbf{p}_{1}$ \\
\hline $\begin{array}{l}\text { Before cycling } \\
\text { loading }\end{array}$ & & & \multirow{4}{*}{$59.392^{*}$} & \multirow{4}{*}{$<0.001^{*}$} \\
\hline Min. - Max. & $27.20-27.80$ & $18.20-19.20$ & & \\
\hline Mean \pm SD. & & $18.59 \pm 0.37$ & & \\
\hline Median(IQR) & $\begin{array}{c}27.50 \\
(27.30-27.65)\end{array}$ & $\begin{array}{c}18.55 \\
(18.25-18.85)\end{array}$ & & \\
\hline $\begin{array}{l}\text { After cycling } \\
\text { loading }\end{array}$ & & & \multirow{4}{*}{$73.087^{*}$} & \multirow{4}{*}{$<0.001^{*}$} \\
\hline Min. - Max. & $24.10-25.20$ & $13.10-13.90$ & & \\
\hline Mean \pm SD. & $24.61 \pm 0.34$ & $13.49 \pm 0.26$ & & \\
\hline Median(IQR) & $\begin{array}{c}24.65 \\
(24.40-24.75)\end{array}$ & $\begin{array}{c}13.50 \\
(13.30-13.65)\end{array}$ & & \\
\hline $\mathbf{t}_{2}\left(\mathbf{p}_{2}\right)$ & $23.267^{*}\left(<0.001^{*}\right)$ & $27.261^{*}\left(<0.001^{*}\right)$ & & \\
\hline Decrease & & & \multirow{4}{*}{$9.924^{*}$} & \multirow{4}{*}{$<0.001^{*}$} \\
\hline Min. - Max. & $2.50-3.50$ & $4.50-6.10$ & & \\
\hline Mean \pm SD & $\downarrow 2.88 \pm 0.35$ & $\downarrow 5.10 \pm 0.53$ & & \\
\hline Median(IQR) & $\begin{array}{c}2.85 \\
(2.55-3.10)\end{array}$ & $\begin{array}{c}5.10 \\
(4.65-5.35)\end{array}$ & & \\
\hline$\%$ of Decrease & & & \multirow{4}{*}{$18.026^{*}$} & \multirow{4}{*}{$<0.001^{*}$} \\
\hline Min. - Max. & $9.03-12.68$ & $24.46-31.77$ & & \\
\hline Mean \pm SD & $\downarrow 10.46 \pm 1.25$ & $\downarrow 27.40 \pm 2.35$ & & \\
\hline Median(IQR) & $\begin{array}{c}10.36 \\
(9.36-11.25)\end{array}$ & $\begin{array}{c}27.64 \\
(25.48-28.38)\end{array}$ & & \\
\hline
\end{tabular}

\section{$t_{1}$ : Student t-test}

t2: Paired t-test

$\mathrm{p}_{1}$ : $\mathrm{p}$ value for comparing between the studied groups $\mathrm{p}_{2}$ : $\mathrm{p}$ value for comparing between before and after cycling loading in each group

*: Statistically significant at $\mathrm{p} \leq 0.05$

Group I: OT-Equator with smart box attachment

Group II: Angled positioner attachment

\section{DISCUSSION}

The "All-on-4 "treatment concept was established by Paulo Malo with straight and angled multi-unit abutments, to supply edentulous patients with a directly loaded full arch restoration with four implants only. In severely resorbed mandible, tilting of posterior implants makes it possible to achieve good bone support without interfering with mental foramina (14). Tilted implants placement might preclude the use of conventional IOD abutments, requiring the need for divergence correcting attachments (15).

Negm (16) also compared stress distribution generated from two types of attachment used for implant mandibular overdenture (OT-Equator and Locator) using both strain gauge analysis and finite element analysis. She concluded that the distribution of stresses at the peri-implant tissues showed lower magnitude when using OT-Equator.

Ammar et al., (17) evaluated the mandibular IOD constructed with OT-Equator attachment system both clinically and radiographically. Clinical and radiographical results revealed insignificant statistical differences in peri-implant probing depth, clinical attachment level, modified plaque index, modified gingival index, implant stability and marginal bone levels between different follow-up periods. The results showed that the clinical and radiographical results revealed insignificant differences in PIPD, CAL, MPI, MGI, implant stability quotient and marginal bone height between different followup periods. They concluded that the IOD with OT-Equator attachments might be recognized as being predictable and successful treatment option.

In this study, The OT-Equator with smart box attachment was selected for the evaluation, as it is considered a new attachment with a special design which has an inner tilting mechanism that enables a passive insertion with divergent implants up to 50.0 degrees, and according to our knowledge, there is no previous research has been done regarding its efficiency in mandibular IRO following the all-on-four concept. The Angled Positioner attachment was selected for comparison with the OT-Equator with smart box attachment because the Angled Positioner attachment was compatible with the implant system, which is related to the OT-Equator with smart box attachment.

Epoxy resin was selected for the installation of implant as it has suitable elastic modulous for bone analog material (approximately $20 \mathrm{GPa}$ ). To imitate the resiliency of soft mucosal tissue of the edentulous mandible, the surface of the cast replica was covered by uniform layer of A- silicone based soft lining material (9). A 3D printed surgical guide (Form labs, Somerville, MA, USA) was used to ensure the precise location of bilateral posterior implant drilling with 25.0 degree angulation after scanning of the epoxy model.

The force of retentivity of the studied overdentures were measured by using the universal testing machine, the model was secured to the lower member of the universal machine testing via the 90-degree, custom-made jig, to allow the tensile force to be perpendicularly applied to the occlusal plane as much as probable to mimic axially focused dislodging forces when a denture is working. And used a T-shaped acrylic resin plate for the force of retentivity as it created the point-of-load application in the center of the mandibular arch. This design decreased the calculation faults possibility from the unrestrained slack difference when 2 or more chains were used to attach to the testing device (18).

The universal machine of testing was set with a $50.0 \mathrm{~mm} / \mathrm{min}$ crosshead speed to simulate the speed of dislodging of a prosthesis from the residual alveolar ridge through mastication (19) and the extension was approximately with $6.0 \mathrm{~mm}$ as the vertical height of the two attachment was $5.50 \mathrm{~mm}$. The computer connected to the universal machine of testing recorded the peak load of dislodgment to decide the final and initial force of retentivity of the two attachment system.

A cyclic machine of loading was utilized to simulate inserting and removing the sixteen overdentures. Each overdenture was exposed to 1000 cycles, being like the median number of insertion and removal cycles in one year established on an average of three removal-insertion cycles/d $(12,13)$. 
A statistically significant increase of force of retentivity was found between the OT-Equator with smart box group (study group) when compared with the Angled Positioner group (control group) when the force of retentivitys of all different resilient nylon caps where compared with each other before and after cyclic loading. The highest usual complication of implant overdentures is attachment retention loss (19).

These results were in agreement with the study of Gabriele Cervino et al (20), who compared the retention of OT Equator ${ }^{\circledR}$ Smart Box and Locator ${ }^{\circledR}$ R-TX. Attachments were mounted in two different configurations of the divergence angle: $10^{\circ}$ and $50^{\circ}$. The drop retention power ends up being steady after some time. The Locator ${ }^{\circledR}$ R-TX connection encountered a quicker decrease of the retention power than the OT Equator ${ }^{\circledR}$ Smart Box. Both tried frameworks encountered a high drop in retention; this drop would in general balance out after 1.5 years of utilization, and it related to the divergence angle. The OT Equator ${ }^{\circledR}$ Smart Box system underwent this loss of retention more gradually than the Locator ${ }^{\circledR R}-\mathrm{TX}$.

The study was with disagreement with Tomas NM et al.,(21) who compared the retaining capacity of 2 overdenture systems of attachment: Locator ${ }^{\circledR}$ and Equator. They found that, both the Locator and the OT Equator systems maintain clinically acceptable retention after 10 years usage.- Retention increases from baseline values until around the 1000-cycle mark (representing eight months functional life). Retention values were like for the 2 systems till the 7,500th cycle (5 years). After the 7,500-cycle point, measurably critical contrasts in retention develop between the two frameworks with OT Equator going through a more noteworthy loss of retention than Locator.

\section{CONCLUSIONS}

Centered on the outcomes of this in vitro study, the subsequent conclusions were made:

1. Retentive caps of OT-Equator with Smart Box and of Angled Positioner provide significantly different levels of retention which decreased after cyclic loading.

2. The OT-Equator with smart box attachment group showed favorable force of retentivity compared with the Angled Positioner attachment group after 1000 cycling loading.

3. The OT-Equator with smart box connection appeared to be a predictable and successful treatment option when utilized with implant assisted overdenture following the allon-four concept.

\section{INTEREST CONFLICTION}

No potential interest confliction related to this article was described.

FUNDING

The author s received no specific fundings for this work

\section{REFERENCES}

1. Felton D. Edentulism and comorbid factors. J Prosthodont. 2009;18:88-96.

2. Emami E, de Souza RF,KabawatM,Feine JS. The impact of edentulism on oral and general health.Int J Dent 2013;2013:1-7.

3. Krennmair G, Seemann R, Fazekas A, Ewers R, Piehslinger E.Patient preference and satisfaction with implant-supported mandibular overdentures retained with ball or locator attachments: a crossover clinical trial. INT J ORAL MAX IMPL.2012 Dec 1;27(6).

4. Anas El-Wegoud M, Fayyad A, Kaddah A, Nabhan A. Bar versus ball attachments for implant-supported overdentures in complete edentulism: A systematic review. Clin Implant Dent Relat Res. 2018;20:243-50.

5. AlqutaibiAY,Kaddah AF. Attachments used with implant supported overdenture. Int Dent Med J Adv Res. 2016;2:1-5.

6. Payne AG,AlsabeehaNH,Atieh MA, Esposito M, Ma S,Anas El-Wegoud M. Interventions for replacing missing teeth: Attachment systems for implant overdentures in edentulous jaws. Cochrane Database Syst Rev. 2018;10:CD008001

7. Satti AA. Comparison of Retentive properties of two Attachment Systems in Mandibular Overdentures-An in vitro study.M.Sc.Thesis.Restorative DentistryDepartment.Faculty of Dentistry and World Health Organization (WHO) Oral Health Collaborating Centre, University of the Western Cape. 2013.

8. Rhein83 USA Product Catalog 2015-2016.

9. Lee CK, Karl M, Kelly JR. Evaluation of test protocol variables for dental implant fatigue research. Dent Mater. 2009;25:1419-25.

10. Sinclair PM, Little RM. Maturation of untreated normal occlusions. Am J Orthod. 1983;83:114-23.

11. Petropoulos VC, Smith W, Kousvelari E. Comparison of retention and release periods for implant overdenture attachments. Int J Oral Maxillofac Implants. 1997;12:176-85.

12. Chung KH, Chung CY, Cagna DR, Cronin RJ. Retention characteristics of attachment systems for implant overdentures. J Prosthodont. 2004;13:221-6.

13. Choi JW, Bae JH, Jeong CM, Huh JB. Retention and wear behaviours of two implant overdenture stud-type attachments at different implant angulations. J Prosthet Dent. 2017;117:628-35.

14. Taruna M, Chittaranjan B, Sudheer N, Tella S, Abusaad M. Prosthodontic perspective to all-on-4® concept for dental implants. J Clin Diagn Res. 2014;8:ZE16-9.

15. Afrashtehfar KI. The all-on-four concept may be a viable treatment option for edentulous rehabilitation. Evid Based Dent. 2016;17:56-7.

16. Negm R. Analysis of stresses distributed from two types attachment used for implant mandibular overdenture. Master Thesis, Faculty of dentistry, Alexandria University 2015.

17. Ammar N. Clinical Evaluation of the implant retained overdenture with OT-Equator Attachments. Master Thesis, Faculty of dentistry, Alexandria University 2016.

18. Petropoulos VC, Smith W, Kousvelari E. Comparison of retention and release periods for implant overdenture attachments.Int J Oral Maxillofac Implants. 1997;12:176-85.

19. Hemmings KW, Schmitt A, Zarb GA. Complications and maintenance requirements for fixed prostheses andoverdentures in the edentulous mandible: a 5-year report. Int J Oral Maxillofac Implants. 1994;9:191-6.

20. Cervino G, Montanari M, Santonocito D, Nicita F, Baldari R, De Angelis C, Storni G, Fiorillo L. Comparison 
of Two Low-Profile Prosthetic Retention System Interfaces: Preliminary Data of an In Vitro Study. Prosthesis. 2019;1:54-60.

21. Mínguez-Tomás N, Alonso-Pérez-Barquero J, Fernández-Estevan L, Vicente-Escuder Á, Selva-Otaolaurruchi EJ. In vitro retention capacity of two overdenture attachment systems: Locator ${ }^{\circledR}$ and Equator ${ }^{\circledR}$. J Clin Exp Dent. 2018;10:e681-6. 